\title{
The Effect of Garden Path Technique of Grammar Instruction on Learning Superlative and Comparative Adjectives
}

\author{
Omid Allaf-Akbary \\ Department of Language and Literature, University of Mohaghegh Ardebili, Ardebil, Iran
}

Email address:

omid_ak2000@yahoo.com

To cite this article:

Omid Allaf-Akbary. The Effect of Garden Path Technique of Grammar Instruction on Learning Superlative and Comparative Adjectives. International Journal of Language and Linguistics. Vol. 3, No. 4, 2015, pp. 217-221. doi: 10.11648/j.ij11.20150304.14

\begin{abstract}
Grammar learning is considered to be one of the major parts of any language bringing about some difficulty in the course of language teaching and learning. Particularly, due to lack of enough language input, learners in foreign language contexts suffer from such trouble more than those in second language contexts. On way through which the teachers can help their learners to tackle such a demanding job is to accompany the grammar instruction with a promising garden path technique. That is because such a technique can be used in the class as a corrective feedback and it also helps the learners and teachers to learn and teach grammatical points implicitly. It is believed that since garden path technique makes an attempt to be used indirectly, it can help the learners to enjoy the learning and be away from the boring explanation of grammatical point. The present study investigates the possible effect of garden path technique, grammar instruction, in forming comparative and superlative adjectives, some of which are confusing and irregular. To this end, 40 elementary learners were selected and assigned into two groups of experimental and control groups. Then, 80 confusing and irregular forms of comparative and superlative adjectives taking out of piloting phase were taught to the experimental group using garden path technique. However, those in the control group were required to follow the regular class of the institute through American English File one. No treatment was given to the control group. Then, both experimental and control groups received a posttest in the form of ten pictures of different features to describe using the comparative and superlative adjectives. The posttest items were based on the 80 target adjectives obtained from the piloting phase. The answers were compared applying an independent samples t-test. The results indicated that the garden path group had a better performance compared to the picture counterpart in describing pictures using the comparative and superlative adjectives. This study might have messages for both language teachers and learners as well as syllabus designers.
\end{abstract}

Keywords: Garden Path Technique, Grammar Learning, Picture Description

\section{Introduction}

It is generally believed that most of the EFL teachers are faced with a variety of techniques for grammar instruction in their classrooms. However, regarding grammar instruction in an EFL context, there are many types of difficulties faced by second language learners and teachers. The teachers make an effort to find ways of overcoming them and provide the learners with an effective grammar instruction. The critical question that has remained unanswered is how to teach grammar effectively. Cook \& Singleton (2014) claim that " grammar is just as important in a second language: we would not do very well in conversation in a second language if we didn't know its basic word order, its common inflections and its system of articles" (p. 58). Although Gass et.al (2003) put forward the idea that awareness of target form alone does not lead to its acquisition unless the formulation of explicit rules is presented, other studies (e.g., Rosa et. al 2004) state that if second language learners are only aware of target form, they can provide the opportunities to facilitate the acquisition of target forms. Ellis et. al (2002) maintain that attending to the linguistic form results from meaning centered activities and communicative tasks.

Gass, Svetics and Lemelin (2003) examined the impact of attention on the learning of different parts of language and how this impact is interacted with language proficiency. The results of the study demonstrated that attention had a significant effect on grammar learning. The study also came 
to this conclusion that attention was most influential during the early stages and the least influential during the later stages.

Park (2003) investigated the question whether externallycreated salience might lead to learners' internally generated salience. The findings were that increasing the perceptual salience of target linguistic forms did not result in learners' noticing of forms. Another result of the study was that noticing linguistic forms was affected by such factors as learner readiness, knowledge of first language, and second language learning experience.

Farrokhi (2005) made an attempt to determine the possibility of integrating form-focused instruction and communicative interaction regarding error correction. The results showed that 'marked recast' could be considered to be a good corrective feedback combining focus on form and focus on meaning at the level of error correction.

According to Morelli (2003), second language learners perceived themselves as having a better attitude towards grammar instruction in context, while performing better after coming up with the traditional grammar instruction.

ELkilic \& Akca (2008) provided a detailed statement about positive attitudes of learners learning English grammar at a private primary EFL classroom towards studying grammar. A little more than fifty percent of their participants stated to enjoy grammar very much and only approximately ten percent reported having some difficulty in learning and remembering grammar. Eun (2010) contextualized grammar teaching using authentic materials resulted that grammar is not boring at all but it can be dynamic and interesting when authentic materials are used to teach grammar.

There are various ways in which grammar techniques are classified. The question which is left unanswered is not whether the grammar is taught or not but the question is which techniques(s) can be more influential than others. Tommasello and Herron (1989) used "Down to the garden path" technique to prove it a promising technique. This technique follows a guideline through which the typical errors were induced and immediately corrected. Down the garden path technique appears to support learners to make a distinction between their own erroneous utterances and the correct target-language utterances. Nunan (2003) stated that "in order to encourage students to process the target structure somewhat more deeply than they might otherwise do, the task is set up to get students to overgeneralize. It thus leads them into error. This is a technique base on inductive learning." (p. 162).

\subsection{Purpose of the Study}

This study aims to use the garden path technique in a class of elementary level to demonstrate whether garden path technique can contribute to the forming of comparative and superlative adjectives. The rationale behind selecting garden path technique is that it is based on inductive learning and no studies have been done on the effect of this technique on improving learners' way of forming both comparative and superlative adjectives. More specifically, this research attempt tries to answer the following research question:

\subsection{Research Question}

RQ: Does garden path technique of grammar instruction help elementary learners learn the confusing form of both comparative and superlative adjectives?

\section{Methodology}

\subsection{Participants}

After piloting phase, fifty elementary learners were selected from Rezvan language institute in Ardebil, Iran. They were known as main participants. Their age range was between 18 to 24 . They attended the class twice a week for nine sessions. All participants had been learning English for a year as a foreign language. And they were mainly university students or school students and were studying English for the purpose of finding a better job or achieving higher degrees in their course of education.

\subsection{Design}

The design of the study was based on a quasi-experimental design in which no randomization was done. As random selection and assignment of students were almost impossible, we had to employ intact classes. Learners were selected at elementary levels. In order to follow the research question, the participants were divided into two groups, control and experimental group. Each group received a pretest and after treatment there was a posttest for each one to determine the effect of the treatment.

\subsection{Instruments}

In order to make sure of the participants homogeneity at the elementary level, the topnotch placement test was administered. Based on the treatment which is forming the superlative and comparative adjectives through garden path technique, the researcher administered two different grammatical tests in this study, one in the piloting stage and one in posttest stage. The purpose of the piloting stage was to identify the problematic cases of comparative and superlative adjectives to be worked on in the treatment sessions. The format of the piloting phase was multiple choice and of posttest was picture description. That is, comparing pictures using comparative and superlative adjectives.

\subsection{Procedure}

For the purpose of the learners' homogeneity to be achieved, the researcher administered a language proficiency test, topnotch placement test. Out of 110 learners 70 of them were homogeneous in terms of elementary level. Having made sure of their equal status, the researcher selected 20 learners out of seventy as a piloting group. The rationale behind the piloting group in the study was to identify the learners' gap in forming the comparative and superlative adjectives. By learners' gap, it means that the confusing and 
irregular adjectives were identified to be worked on in the experimental group. Through piloting phase 80 confusing and irregular adjectives were identified. By confusing and irregular adjectives, the researcher means those which don't follow the formal and regular rule of forming superlative and comparative adjectives. The remaining number of participants was classified as control and experimental group each of which consisted of 25 learners. The experimental group received the treatment. It took nine sessions for each group to follow the researcher's instruction. Each session lasted for 90 minutes. Sixty minutes for the usual class activity dictated by the institute and thirty minutes for the treatment instruction in experimental group. Both groups studied the specified course book of the institute, American English File one. In the first session both the experimental group and control group received the formal instruction of comparative and superlative adjectives in English grammar through which the learners became familiar with the rules of forming those adjectives. The first session was only to explain the formal rules. From the second session to the ninth, in addition to the course book, the experimental group followed the treatment lasting thirty minutes each session. Using the confusing and irregular adjectives obtained from piloting phase, the researcher in experimental group provided the learners with a variety of pictures to describe. For example, the first picture of the first session in the experimental group was fish in three different sizes. It was given to the learners to produce the comparative and superlative adjectives by comparing the pictures. Each session after the regular study of the course book, the learners in the experimental group received ten items of different sizes in pictorial forms and the confusing and irregular adjectives below the pictures and they were asked to compare the pictures from different perspectives. Describing the pictures, the learners found most of the adjectives confusing and the researcher made sure that the piloting phase for selecting the adjectives was helpful. The researcher used the garden path technique whenever learners committed errors. It took nine sessions to complete the adjectives and picture description. The control group didn't receive any treatment. They just followed the institute syllabus studying American English File one. Finally, there was a posttest in terms of the target adjectives to determine whether the garden path technique was effective. The posttest was in the form of picture description though which the learners described ten pictures. The schematic representation is as follows (Figure 1.):

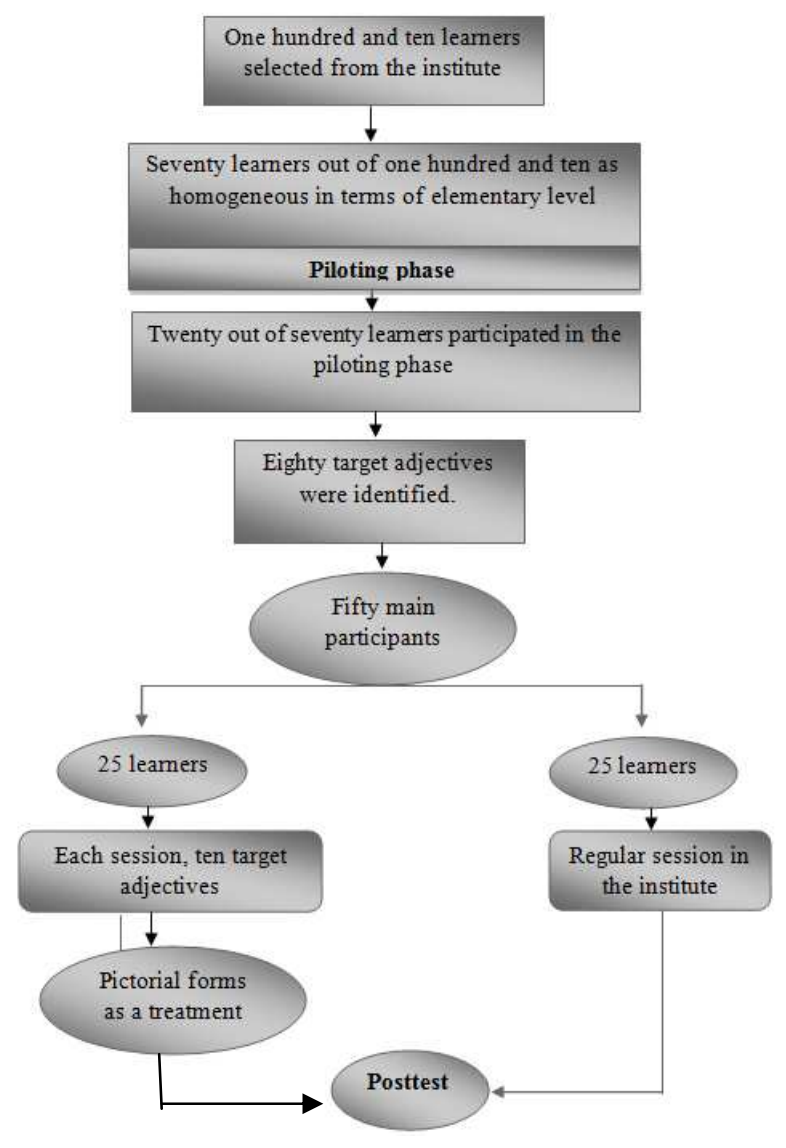

Figure 1. Design of the Study.

\subsection{Data Analysis}

The purpose of this section is to determine if the variation observed among the mean scores of the two groups participating in the study was larger than would be expected by chance. The scores of the retention assessment were fed into the Statistical Package for Social Sciences (SPSS) 
version 16. Then using a t-test the two groups were compared to spot any possible statistically significant difference. What follows is first the descriptive statistics table then the table of t-test:

Table 1. Group Statistics

\begin{tabular}{llllll}
\hline Grouping & N & Mean & $\begin{array}{l}\text { Std. } \\
\text { Deviation }\end{array}$ & $\begin{array}{l}\text { Std. } \\
\text { Error } \\
\text { Mean }\end{array}$ \\
\hline Score & $\begin{array}{l}\text { Experimental } \\
\text { "Garden Path" } \\
\text { Control "Regular } \\
\text { Sessions" }\end{array}$ & 20 & 7.10 & 1.033 & .327 \\
\hline
\end{tabular}

As the Table 1 shows, the total number of subjects is 40 (in fact two groups 20 each). The mean scores for experimental (Garden path technique) and control group (Regular sessions) are 7.10 and 4.20 respectively with the standard deviations of 1.033 for the former and .994 for the control group. At first glance, as the mean scores indicate, there is a perceptible difference between the participants in terms of their performance of 10 picture descriptions which were the basis of the assessment. But the question is: Does this difference reach statistical significance or not? To this end, an independent samples t-test is run in order to pinpoint any possible significant difference from a statistical point of view:

Table 2. Independent Samples Test.

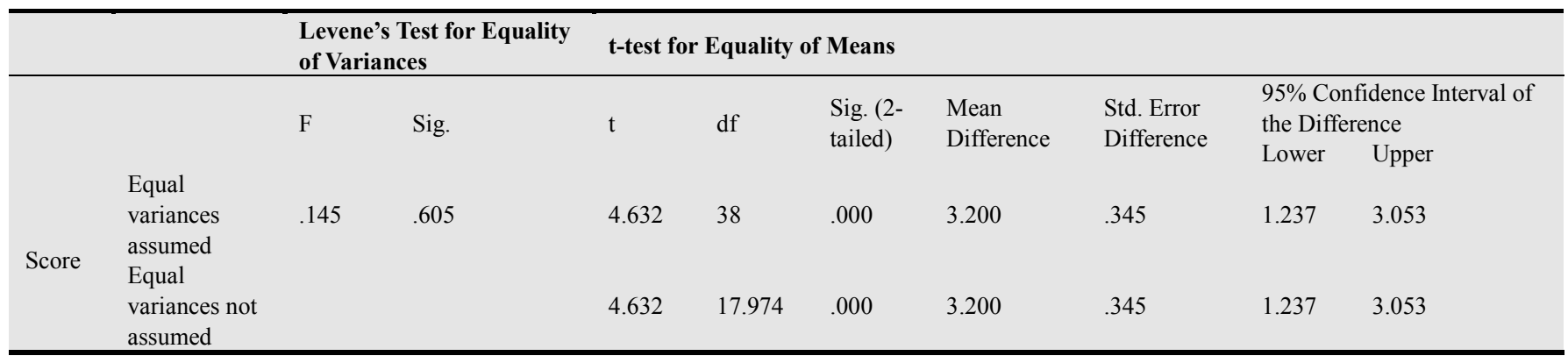

\section{Results and Discussion}

As it was mentioned earlier, the purpose of the assessment was to examine whether the elementary learners were able to produce the confusing and irregular adjectives by looking at the pictures within which there were different sizes or forms of an item. The garden path group gave a mean of 7.10 correct forms of adjectives and the control group 4.20 correct forms of adjectives. The difference between the means of answers of both groups was thus 4.9 adjective forms. As it can be observed from the Table 2, the F value is .145 meaning that we have not violated t-test's assumption in this regard (Dörnyei, 2007). Based on the results of Table 2, the value of Sig. (2-tailed) is .000 which is an indication of a significant difference between the experimental and control groups. Therefore, it should be determined which line in the table should be used in reporting the results. It is shown that the value of Sig. is .605 which is larger than .05 . So the first line of the table is reported. Taking a look at the first line, it is obvious that Sig. (2-tailed) is .000 and less than .05. As a result, we can conclude that there is a statistically significant difference between the experimental and control groups. In other words, the results of the independent samples t-test confirmed that the observed difference was significant and revealed the effect of the garden path grammar instruction of adjective forms.

As it was alluded in our research question, the experimental group, garden path, had a good performance in comparison to the control group, regular class, in learning how to produce the confusing and irregular form of comparative and superlative adjectives. It seems that when garden path technique is used in teaching and learning grammatical points, the ultimate achievement is accomplished by more efficiency and effectiveness.

It is necessary to mention that the findings of the present study and similar studies must be interpreted with caution. Even if the findings in the literature in this domain are somewhat contradictory, it would nevertheless be interesting to assess the effect of garden path grammar technique on learning different confusing and irregular forms of comparative and superlative adjectives in second language acquisition.

\section{Conclusion and Implications}

The present study aimed to examine the effect of garden path technique on leaning different confusing and irregular forms of comparative and superlative adjectives by the elementary English language learners. As it turned out, the garden path group outperformed the control group in producing the correct form of comparative and superlative adjectives. Language teachers particularly those who are busy with teaching elementary learners have to remember the findings of the present research endeavor. They must try as far as possible to make use of garden path technique in their classrooms. As it went earlier, this helps to have an active classroom in which their learners energetically spend their full potential on learning new stuff.

\section{References}

[1] Dörnyei, Z. (2007). Research methods in applied linguistics: Quantitative, qualitative and mixed methodologies. Oxford: Oxford University Press. 
[2] ELkilic, G., \&Akca, C. (2008). Attitudes of the Students Studying at Kafkas University Private Primary EFL Classroom towards Storytelling and Motivation. Journal of Language and Linguistic Studies, 4(1), 1-22.Cook \& Singleton (2014)

[3] Eun JO. 2010. Contextualizing grammar teaching using authentic materials. Retrieved from http://www.fbcinc.com/e/LEARN/e/korean2010/presentations/ on April 28, 2010

[4] Farrokhi, F. (2005).Revisiting the ambiguity of recasts. Journal of Faculty of Letters and Humanities, 195, 61-101.

[5] Gass, S., Svetics, I., \& Lemelin, S. (2003). Differential effects of attention. Language Learning, 53(3), 497-545.

[6] Morelli, J. A. (2003). Ninth Graders' Attitudes toward Different Approaches to Grammar Instruction. Unpublished
Dissertation. The Graduate School of Education, Fordham University, New York.

[7] Nunan, D. Editor. (2003). Practical English Language Teaching. Mc GrawHill.

[8] Park, E. S. (2003). Constraints of Implicit Focus on Form. Teachers College Columbia University Working papers in TESOL and Applied Linguistics, Vol. 4, No. 2.

[9] Rosa, Elena \& Leow, Ronald P. (2004). Computerized taskbased exposure, explicitness, type of feedback, and Spanish L2 development. Modern Language Journal, 88(2), 192-216.

[10] Tomasello, M. \& Herron, C. (1989). Feedback for Language Transfer errors: The garden Path Technique. Studies in Second Language Acquisition, 11, 385-395.

[11] V. Cook \& D. Singleton (2014). Key Topics in Second Language Acquisition. Bristol: Multilingual Matters. 